\title{
Public Health and Community Medicine
}

RESEARCH ARTICLE

\section{Knowledge and Perceived Susceptibility of Cardiovascular Diseases (CVDs) among Saudi Female Teachers}

\author{
Ibtisam AL-Tamimi, MD, MPH and Amen Bawazir, MD, $\mathrm{PhD}^{2^{*}}$ \\ ${ }^{1}$ Department of School Health, General Directorate of Health Affairs-Riyadh, Ministry of Health, Saudi Arabia \\ ${ }^{2}$ Community and Environmental health, College of Public Health and Health Informatics, King Saud Bin \\ Abdulaziz University for Health Sciences, Saudi Arabia
}

*Corresponding author: Amen Bawazir, MD, PhD, Professor, Community and Environmental health, College of Public Health and Health Informatics, King Saud Bin Abdulaziz University for Health Sciences, King Abdulla International Medical Research Center, 22490, Riyadh 11426, Saudi Arabia, Tel: +966114295422, Fax: +966114295463

\begin{abstract}
Background: The purpose of this study was to examine the current knowledge levels, health beliefs, personal risk factors, and health-promoting behaviors related to cardiovascular diseases (CVDs) among female Saudi teachers in Riyadh city.

Methods: This study featured a cross-sectional descriptive design. A survey method was used to collect data from 400 women teachers who were randomly selected from ten public schools in five regions of Riyadh city, Saudi Arabia. A pretested questionnaire was used to collect data.

Results: The mean age ( \pm standard deviation) of the surveyed women was $40.4 \pm 6.5$ years. Only $44.8 \%$ of the participating female teachers showed adequate knowledge of CVD, and very few of the teachers felt susceptible to CVD $(13.3 \%)$. Of most concern, however, was the fact that although most participants (94\%) identified physical activity as a preventive factor for heart disease, a significant proportion $(76 \%)$ did not participate in regular physical activity. Furthermore, only half of the participants $(53 \%)$ were in the habit of consuming fruits and vegetables on most days of the week.

Conclusions: Our findings conclude that most of the participants involved in this study did not perceive themselves to be susceptible to CVD. It is therefore very important to develop adequate health education public programme to motivate women in changing their risky behavior and to engage them in positive health promotion activities aiming to reduce the risk of CVD.
\end{abstract}

\section{Keywords}

Cardiovascular, Saudi Arabia, Knowledge, Health belief model, Women, Teachers

\begin{abstract}
Abbreviations
CVD: Cardio Vascular Diseases; HBM: Health Belive Model; WHO: World Health Organization; KSA: Kingdom of Saudi Arabia; AOR: Adjusted Odds Ratio; OR: Odds ratio; SES: Socio-Economic Status; IRB: Institutional Review Board; CPHHI: College of Public Health and Health Informatics; KAIMRC: King Abdullah International Medical Research Center
\end{abstract}

\section{Introduction}

Cardiovascular disease (CVD) is the leading cause of death worldwide, is responsible for a significant number of disabilities and causes widespread economic impact [1]. Furthermore, while CVD is considered to be the leading cause of death and major risk factor to health among women, the fact of the matter is that this disease is largely preventable [2-4]. In the middle-eastern region, including Saudi Arabia, ischaemic heart disease has been reported as being the leading cause of death [5]. In the 2010 report published by the World Health Organization (WHO) and the Ministry of Health (MOH) Statistical Yearbook of Saudi Arabia, CVDs were reported to be the cause of $42 \%$ of deaths by non-communicable disease in Saudi Arabia [6]. Other studies state that ischemic heart disease was the primary cause of death among both women (17.9\%) and men (19.3\%) in Saudi Arabia over recent years [3,7-9].

A range of studies from across the world has confirmed that misperceptions relating to CVD still persists

Citation: AL-Tamimi I, Bawazir A (2020) Knowledge and Perceived Susceptibility of Cardiovascular Diseases (CVDs) among Saudi Female Teachers. Int Arch Public Health Community Med 4:045. doi. org/10.23937/2643-4512/1710045

Accepted: June 16, 2020; Published: June 18, 2020

Copyright: (c) $2020 \mathrm{AL}-\mathrm{Tamimi}$ I, et al. This is an open-access article distributed under the terms of the Creative Commons Attribution License, which permits unrestricted use, distribution, and reproduction in any medium, provided the original author and source are credited. 
and that women of all ages lack an adequate knowledge of CVD and related risk factors. It is also evident that these observations are related to such women not engaging in preventative behavior $[10,11]$. Until women perceive themselves as being vulnerable to CVDs, they will not realize the importance of prevention [12].

Men and women in the Kingdom of Saudi Arabia (KSA), are both exposed to similar risk factors which place them at a risk of developing CVD. However, women show a higher rate of risk factors related to obesity, physical inactivity and unbalanced diatery habits [1320]. Indeed, the prevalence of obesity and self-reported physical inactivity among Saudi women has increased significantly over the last ten years $[18,19]$. In fact, the incidence of obesity increased from $23.6 \%$ to $44.0 \%$ while the incidence of physical inactivity increased from $84.7 \%$ to $98.1 \%$ [17]. This prominent increase in the risk of CVD risk among young women has been attributed to unhealthy dietary habits and a sedentary lifestyle [20].

Over two-thirds of women who suffered sudden death from coronary heart disease had no recognizable preceding symptoms, making the prevention of coronary heart disease in women a significant priority [21]. This disease affects women in a much more severe manner than men; for instance, women are more likely to die within the first year of having a heart attack than men [22]. As life expectancy continues to increase in the population of Saudi Arabia, and economies become more industrialized, the burden of CVDs upon women, and the economy of the country,will continue to increase [23]. The presence of a single risk factor at 50 years of age is associated with a substantially increased lifetime absolute risk for CVDs and shorter survival [24]. The prevention of CVDs is therefore essential to the health of every woman and every nation with particular focus on the reduction of related risk factors [25]. Many previous studies have confirmed that women of all ages do not have an adequate knowledge of heart disease, and related risk factors, but perceive breast cancer as representing their most serious health threat [26-28]. Women are unlikely to accept the potential threat posed by their individual behavior, or appreciate the value of health education messages regarding the prevention of CVDs $[29,30]$. The perception of susceptibility to CVDs will increase the likelihood that an individual will adopt health promoting behaviors [28]. Some studies have shown that perceived risk susceptibility and perceived severity are highly correlated with the engagement of preventative behaviors [31,32].

In Saudi Arabia, knowledge relating to CVDs, and its associated risk factors, have not been sufficiently investigated, particularly with regards to gender. The prevalence of obesity and physical inactivity has increased significantly, resulting in an elevated risk of CVD. Consequently, there is an urgent need to investigate the different factors that might hinder the application of pre- ventative approaches to CVDs among women in Saudi Arabia. This study therefore aims to examine current knowledge levels and perceptions about CVDs among Saudi women. In addition, the study aims to identify which risk factors are associated with increased perceived susceptibility to CVD and which health beliefs are more likely to predict participation in health promoting behavior.

\section{Methods}

This was a cross-sectional descriptive study which was designed to evaluate knowledge of the prevalence and risk factors for cardiovascular diseases among female educators in Riyadh city, KSA. Riyadh city, is the capital and largest city of Saudi Arabia with a population of approximately 9 million people. The system of education in Saudi Arabia includes public and private schools, however, this study only targeted female Saudi teachers in public schools within Riyadh city. There are many non-Saudi female teachers working in private schools in Saudi Arabia, although for the purpose of this study, non-Saudi teachers and non-teaching employees were excluded.

The calculated sample size was 385 to achieve a confidence level of $95 \%$ and a precision of \pm 0.05 margin of error [33]. For an assumption of $4 \%$ incompleteness rate of responses, the survey was inflated to reach up to 400 female teachers. Women in this sample were selected randomly from two schools from each of the five main regions of Riyadh city: East, west, south, north and central region. Consequently, our study featured participants from 10 public schools.

\section{Data Collection Tool}

In order to collect data for this study, we used aquestionnaire targetting CVD in women which has been validated and used previously [34,35]. However, modifications were made to the questionnaire in order to adopt the local context and to allow better understanding of the questions. The questionnaire was pretested with 20 female teachers from schools not included in the final sample. This allowed us to assess the consistency, persistence and validation of the Arabic version of the questionnaire. Analysis showed that the questionnaire had a Cronbach's alpha coefficient of 0.73 , however the resultant Cronbach's alpha level of the different constructs ranged from 0.71 to 0.87 .

All the female teachers present on the day of data collection session were given a short presentation about the importance of the study and were asked to participate in the survey by completing the questionnaire if they wished to do so. Informed consent was therefore obtained from those who agreed to participate and they were enrolled in the study. This study was reviewed and approved by the internal research committee in the College of Public Health and Health Informatics (CPHHI), King Saud bin Abdulaziz University for Health Sciences 
(KSAU-HS) and then by the Institutional Review Board (IRB) at King Abdullah International Medical Research Center (KAIMRC) under \# SP 17/005/R.

The survey instrument consisted of 55 questions designed to measure knowledge, risk factors, health beliefs such as perceived susceptibility using the health belief model (HBM), health-promoting behavior, as well as cues to action as strategy to activate "readiness" which usually provide how-to information, promote awareness, reminders. The HBM is one of the most popular intrapersonal theories most commonly used as conceptual frameworks for understanding and changing health behavior [32]. Health beliefs is the individual perception of risk of contracting a health condition, and the severity of the condition (perceived susceptibility and perceived severity), as well as the perceived benefits minus barriers of taking action to reduce the risk. Moreover, this model is divided into three components: Individual perceptions, modifying factors, and likelihood of action. Individual perceptions include the constructs of perceived susceptibility which is beliefs regarding the possibility of developing a health condition such as CVD and perceived severity/seriousness which is beliefs regarding the seriousness of developing a health condition such as heart disease or leaving it untreated. Health beliefs were measured using seven subscales: General knowledge of CVD (assessed by 9 items), perceived susceptibility ( 7 items), perceived severity ( 5 items), perceived benefits ( 6 items), perceived barriers (10 items), health promotion behaviour ( 5 items) and cues to action ( 7 items). An overall score was then calculated from each construct to demonstrate the overall scope of the promotion behaviour toward CVDs among the female teachers in this study.

The questionnaire was divided into four sections and included a variety of different questions, including multiple choice, true/false and open-ended questions which were either based on a five-point Likert scale (strongly agree, agree, neutral, disagree, strongly disagree) or yes/no types of questions.

The first section of the survey focussed upon women's knowledge and awareness with regards to CVD and consisted of nine questions in which items one tofour were multiple choice questions, and included six response answers. Items 5 to 9 were true/false questions with three possible answers ("true", "false" or "don't know"). Items were coded as categorical variables in which "correct" = 1, and "not correct" and "don't know" $=0$.

The second section of the survey assessed women's health beliefs of CVD using four constructs from the HBM: perceived susceptibility; perceived severity; perceived benefits and perceived barriers addressing health beliefs/perceptions. This part of the survey consisted of 28 items, each with a five-point Likert scale response (ranging from 1 = "Strongly Disagree" to $5=$
"Strongly Agree") in which health beliefs/perceptions were divided into four subscales.

The third section of the survey assessed women's health-promoting behaviors. This section consisted of six items, each with a "yes" and "no" response option. For research questions addressing health-promoting behaviors, a "yes" response on all items was coded " 1 " while a response of "no" was coded as " 0 ".

The fourth and final section of the survey assessed general items such as cues to action from the HBM, personal risk factors for CVD and basic demographic information (for example, level of education). The cues to action health promotion behaviour consisted of five activities. Participants were asked to indicate the number of activites they usually carry out on a daily or weekly basis. These activities were ranged from only one promotion activity, two, three, four, and five activities performed daily to protect herself from CVDs. The responses were coded as either "yes" = 1 or "no" and "don't know" = 0 . In this section and other related sections where the overall level of respondents is measured to be as "high" or "low" level, a cut-off point of $50 \%$ was used to identify these findings.

\section{Statistical Analysis}

Data were first cleaned and then statistical analysis was carried out using the Statistical Program for Social Sciences (IBM SPSS Corp, SPSS Statistics ver. 20, USA). Demographic data (for example, age and educational level) were summarized as descriptive statistics and the Chi-square test was used to test for significant relationships. Logistic regression models were used to identify factors associated with a low score (a score $\leq 50 \%$ ). Variables found to be statistically significant in univariate analyses were also included in the final backward multivariate logistic regression analysis. All tests were two-sided, and statistical significance was considered at a $P$-value of $<0.05$.

\section{Results}

This study aimed to examine the current knowledge levels and perceptions of female Saudi teachers in Riyadh city, with regards to CVD risk factors. In total, there were 400 female teachers who participated, with a mean age of $40.4 \pm 6.5$ years. Half of the study population (50.5\%) were classified into young adult age group (30-39 years), over one third (36.8\%) into a middle age group (40-49 years), and few (12.8\%) in an older adult age group (50-59 years). Most of the participants $(88.8 \%)$ were highly educated andheld a university or higher degree, as seen in Table 1.

Findings in Table 2 revealed unsatisfactory overall scores (<50\% cutoff point) with relation to knowledge, perceived susceptability, perceived severity and cues to actions (44.8\%, 13.3\%, 24.0\%, 33.8\%, respectively). Female teachers showed high scores with relation to 
perceived benefit $(98.0 \%)$ and the conduction of health promotion behaviour (66.0\%). However, over half of the participants $(56.5 \%)$ highlighted perceived barriers towards the implementation of promotion actions for CVDs.

Findings in this study showed that $10 \%$ of the participants perform only one promotion activity, 24\% performed two ctivities, $36 \%$ for three, $20.5 \%$ with four, and only $9.5 \%$ of participants indicated that they routinely perform all 5 activities daily.

Table 3 illustrates the eight major personal risk factors that were measured in this study. The mean number of personal risk factors per woman from the overall 8 scores was $2.99 \pm 1.4$. The most frequently reported personal risk factor was physical inactivity (76.0\%), followed by excessive weight gain and obesity (53.8\%), followed by a family history of heart attack $(43.8 \%)$. The least mentioned risk factor was smoking (3.0\%). Other risk factors, such as high cholesterol, high blood presure, diabetes milletus, or an age $>50$ years were indicated at relatively low incidences of $29.0 \%, 20.0 \%, 19.0$ and $12.8 \%$, respectively.

A comparison of association of the independent categorical variables of knowledge with age groups and

Table 1: Sociodemographic characteristics of the study population.

\begin{tabular}{|l|l|l|l|}
\hline Variables & Characteristics & No. & $\%$ \\
\hline Age group & $30-39$ & 202 & 50.5 \\
\hline & $40-49$ & 147 & 36.8 \\
\hline & $50-59$ & 51 & 12.8 \\
\hline Education level & High school & 45 & 11.2 \\
\hline & University or higher & 355 & 88.8 \\
\hline
\end{tabular}

Table 2: Overall scoresrelated to the health belief model (HBM).

\begin{tabular}{|l|l|l|l|l|}
\hline \multirow{2}{*}{ Construct } & Low & \multicolumn{3}{l|}{ High } \\
\hline & No. & $\%$ & No. & $\%$ \\
\hline Overall Knowledge & 221 & 55.2 & 179 & 44.8 \\
\hline Perceived susceptibility & 347 & 86.8 & 53 & 13.3 \\
\hline Perceived severity & 304 & 76.0 & 96 & 24.0 \\
\hline Perceived benefits & 8 & 2.0 & 392 & 98.0 \\
\hline Perceived barriers & 174 & 43.5 & 226 & 56.5 \\
\hline Health promoting behaviors & 154 & 34 & 246 & 66.0 \\
\hline Cues to action & 265 & 66.2 & 135 & 33.8 \\
\hline
\end{tabular}

education level of the Saudi female teachers using a chisquare test. There was a strong statistical association between women's general knowledge with regards to CVDs and an age. For example, those younger participants (less than 50-years-old) were lesser knowledgeable with cardiovascular disease in comparison to older participants (42.6\% and $40.8 \%$ vs. $64.7 \%$; $P=0.009$ ). However, no association was found between knowledge and the level of education, as seen in Table 4.

A univariate and multivariate regression analysis were used to assess which of the variables (perceived susceptibility, perceived severity, perceived benefits, perceived barriers, selected modifying factors, age, and education) were the strongest predictors of health-promoting behaviors among female Saudi teachers (Table 5). Predictors of health promoting behaviours of CVDs were found to be the same in both univariate and multivariate analysis and identified to be at the level of knowledge of CVDs, perceived benefit, perceived barriers and cues to action. Those with adequate knowledge on CVD were 1.5 times more likely to adopt health promoting behaviour for CVDs than those with inadequate knowledge [Adjusted Odds ratio $(A O R)=1.576$; 95\% Confidance Interval $(\mathrm{Cl})=1.024-2.486 ; P$-value $=$ 0.049]. Those with high perceived benefits were 25.9 times more likely to adopt health promoting behaviour for CVDs than those with low perceived benefits (AOR $=25.929 ; 95 \% \mathrm{Cl}=2.867-234.517 ; P$-value $=0.004)$. Those with low perceived barriers were 1.9 times more likely to adopt health promoting behaviour for CVDs than those with high perceived barriers $(A O R=1.910$; $95 \% \mathrm{Cl}=1.208-3.021 ; P$-value $=0.006$ ) while those with high cues to action were 3.6 times more likely to adopt

Table 3: Affirmative personal risk factors for cardiovascular diseases.

\begin{tabular}{|l|l|l|}
\hline Item & N & $\%$ \\
\hline Not physically active most days of the week & 304 & 76.0 \\
\hline Overweight/obesity & 215 & 53.8 \\
\hline $\begin{array}{l}\text { Immediate family history of heart attack or } \\
\text { heart disease? }\end{array}$ & 175 & 43.8 \\
\hline High cholesterol & 116 & 29.0 \\
\hline High blood pressure & 80 & 20.0 \\
\hline Diabetes millitus & 76 & 19.0 \\
\hline Age above 50 years & 51 & 12.8 \\
\hline Smoking & 12 & 3.0 \\
\hline
\end{tabular}

Table 4: Association of demographic characteristics with knowledge of cardiovascular disease.

\begin{tabular}{|c|c|c|c|c|c|c|}
\hline \multirow{2}{*}{\multicolumn{2}{|c|}{ Variable }} & \multicolumn{2}{|c|}{ Inadequate knowledge } & \multicolumn{2}{|c|}{ Adequate knowledge } & \multirow{3}{*}{\begin{tabular}{|l}
$\boldsymbol{P}$ value \\
0.009
\end{tabular}} \\
\hline & & \multirow{2}{*}{$\begin{array}{l}\mathbf{N} \\
116\end{array}$} & \multirow{2}{*}{\begin{tabular}{|l|}
$\%$ \\
57.4 \\
\end{tabular}} & \multirow{2}{*}{$\begin{array}{l}\mathbf{N} \\
86\end{array}$} & \multirow{2}{*}{$\begin{array}{l}\% \\
42.6 \\
\end{array}$} & \\
\hline Age group & $30-39$ & & & & & \\
\hline & $40-49$ & 87 & 59.2 & 60 & 40.8 & \\
\hline & $50-59$ & 18 & 35.3 & 33 & 64.7 & \\
\hline \multirow[t]{2}{*}{ Education } & - high school & 21 & 46.7 & 24 & 53.3 & 0.219 \\
\hline & - university or higher & 200 & 56.3 & 155 & 43.7 & \\
\hline
\end{tabular}


Table 5: Univariate and multivariate regression analysis for predictors of health promoting behaviour for cardiovascular diseases.

\begin{tabular}{|c|c|c|c|c|c|c|c|c|}
\hline Variables & Characteristics & Reference & OR & 95\% C.I & $P$-value & AOR & 95\% C.I & $P$-value \\
\hline \multirow[t]{3}{*}{ Age category } & $30-39$ & & - & - & - & - & - & - \\
\hline & $40-49$ & & 0.859 & $0.528-1.396$ & 0.539 & - & - & - \\
\hline & $50-59$ & $\dagger$ & 1.925 & $0.846-4.380$ & 0.119 & - & - & - \\
\hline \multirow[t]{2}{*}{ Education level } & High school & $\dagger$ & - & - & - & - & - & - \\
\hline & University or higher & & 0.949 & $0.461-1.954$ & 0.887 & - & - & - \\
\hline \multirow[t]{2}{*}{ Knowledge } & Inadequate & $\dagger$ & - & - & - & - & - & - \\
\hline & Adequate & & 0.618 & $0.386-0.988$ & 0.044 & 1.576 & $1.0024-2.486$ & 0.049 \\
\hline \multirow[t]{2}{*}{ Perceived susceptibility } & Low & $\dagger$ & - & - & - & - & - & - \\
\hline & High & & 0.540 & $0.259-1.129$ & 0.102 & - & - & - \\
\hline \multirow[t]{2}{*}{ Perceived severity } & Low & $\dagger$ & - & - & - & - & - & - \\
\hline & High & & 1.147 & $0.680-1.936$ & 0.607 & - & - & - \\
\hline \multirow[t]{2}{*}{ Perceived benefits } & Low & $\dagger$ & - & - & - & - & - & - \\
\hline & High & & 0.041 & $0.004-0.381$ & 0.005 & 25.929 & $2.867-234.517$ & 0.004 \\
\hline \multirow[t]{2}{*}{ Perceived barriers } & Low & $\dagger$ & - & - & - & - & - & - \\
\hline & High & & 1.896 & $1.190-3.022$ & 0.007 & 1.910 & $1.208-3.021$ & 0.006 \\
\hline \multirow[t]{2}{*}{ Cues to action } & Low & $\dagger$ & - & - & - & - & - & - \\
\hline & High & & 0.240 & $0.133-0.434$ & $<0.001$ & 3.583 & $2.096-6.126$ & $<0.001$ \\
\hline
\end{tabular}

†: Reference ; OR: Odds ratio, AOR: Adjusted odds ratio.

Table 6: Univariate and multivariate regression analysis for predictors of health promoting behaviour on cardiovascular diseases and perceived susceptability.

\begin{tabular}{|c|c|c|c|c|c|c|c|c|}
\hline Variables & charectaristics & & OR & 95\% C.I & $P$ value & AOR & 95\% C.I & $P$-value \\
\hline \multirow[t]{3}{*}{ Age category } & $30-39$ & $\dagger$ & - & - & - & - & - & - \\
\hline & $40-49$ & - & 1.242 & $0.618-2.496$ & 0.542 & - & - & - \\
\hline & $50-59$ & - & 1.581 & $0.609-4.102$ & 0.346 & - & - & - \\
\hline \multirow[t]{2}{*}{ Education level } & High school & $\dagger$ & - & - & - & - & - & - \\
\hline & University or higher & - & 0.548 & $0.227-1.322$ & 0.181 & - & - & - \\
\hline \multirow[t]{2}{*}{ Knowledge } & Inadequate & $\dagger$ & - & - & - & - & - & - \\
\hline & Adequate & - & 2.377 & $1.225-4.615$ & 0.011 & 2.234 & $1.183-4.218$ & 0.013 \\
\hline \multirow[t]{2}{*}{ Perceived severity } & Low & $\dagger$ & - & - & - & - & - & - \\
\hline & High & - & 1.217 & $0.603-2.456$ & 0.584 & - & - & - \\
\hline \multirow[t]{2}{*}{ Perceived benefits } & Low & $\dagger$ & - & - & - & - & - & - \\
\hline & High & - & 1.147 & $0.118-11.166$ & 0.906 & - & - & - \\
\hline \multirow[t]{2}{*}{ Perceived barriers } & High & $\dagger$ & - & - & - & - & - & - \\
\hline & Low & - & 0.603 & $0.312-1.164$ & 0.132 & - & - & - \\
\hline \multirow[t]{2}{*}{ Cues to action } & Low & $\dagger$ & - & - & - & - & - & - \\
\hline & High & - & 6.532 & 3.323-12.839 & $<0.001$ & 5.929 & $3.098-11.346$ & $<0.001$ \\
\hline
\end{tabular}

†: Reference; OR: Odds ratio; AOR: Adjusted odds ratio.

health promoting behaviour for CVDs than those with low cues to action $(A O R=3.583 ; 95 \% \mathrm{Cl}=2.096-6.126$; $P$-value $=<0.001)$.

Regression analysis (Table 6) was used to identify predictive factors related to the perceived susceptibility for CVDs. In both univariate and multivariate regression models, knowledge and cues of action were identified as predictors for those with adequate perceived susceptability of CVDs among female teachers (AOR $=2.234$; $95 \% \mathrm{Cl}=1.183-4.218, P$-value $=0.013)$.
Those with adequate knowledge on CVD were more than two times likely to adopt health promoting behaviour for CVDs than those with inadequate knowledge $(A O R=2.234 ; 95 \% \mathrm{Cl}=1.183-4.218 ; P$-value $=0.013$ ), while those with high cues to action were around 6 times more likely to adopt health promoting behaviour for CVDs than those with low cues to action $(\mathrm{AOR}=5.929 ; 95 \% \mathrm{Cl}=3.098-11.346 ; P$-value $=<0.001)$.

As indicated in Table 7, a statistically significant difference in adopting health promoting behavior was revealed between respondents who use more cues to 
Table 7: Association between health promotion behavior for cardiovascular diseases and cues to action.

\begin{tabular}{|c|c|c|c|c|c|}
\hline \multirow{3}{*}{ Health promotion behavior } & \multicolumn{4}{|c|}{ Cues to action } & \multirow[b]{3}{*}{$P$-value } \\
\hline & \multicolumn{2}{|l|}{ Low } & \multicolumn{2}{|c|}{ High } & \\
\hline & $\mathbf{N}$ & $\%$ & $\mathbf{N}$ & $\%$ & \\
\hline Eating appropriate amounts of fruit/vegetables & 112 & 59.9 & 75 & 40.1 & 0.012 \\
\hline Non-smoker & 260 & 67.0 & 128 & 33.0 & 0.067 \\
\hline Physically active or exercise adequately & 55 & 57.3 & 41 & 42.7 & 0.033 \\
\hline Monitoring blood pressure & 196 & 62.0 & 120 & 38.0 & $<0.001$ \\
\hline Monitoring blood cholesterol & 101 & 51.8 & 94 & 48.2 & $<0.001$ \\
\hline
\end{tabular}

Table 8: Association between perceived susceptibility and establishedpersonal risk factors.

\begin{tabular}{|c|c|c|c|c|c|}
\hline \multirow{3}{*}{ Personal risk factors } & \multicolumn{4}{|c|}{ Perceived susceptibility } & \multirow{3}{*}{$P$-value } \\
\hline & \multicolumn{2}{|l|}{ Low } & \multicolumn{2}{|c|}{ High } & \\
\hline & $\mathbf{N}$ & $\%$ & $\mathbf{N}$ & $\%$ & \\
\hline History of high cholesterol & 88 & 75.9 & 28 & 24.1 & $<0.001$ \\
\hline History of high blood pressure & 58 & 72.5 & 22 & 27.5 & $<0.001$ \\
\hline History of diabetes/prediabetes & 57 & 75.0 & 19 & 25.0 & 0.001 \\
\hline Family history of heart disease & 139 & 79.4 & 36 & 20.6 & $<0.001$ \\
\hline Overweight or obesity & 178 & 82.8 & 37 & 17.2 & 0.012 \\
\hline Physical inactivity & 263 & 86.5 & 41 & 13.5 & 0.804 \\
\hline Smoking practice & 10 & 83.3 & 2 & 16.7 & 0.723 \\
\hline
\end{tabular}

Data was analyzed by the Chi-square test and was significant if $\mathrm{P}<0.05$.

action compared to those who identified less cues to action. These mainly activities related to eating appropriate amounts of fruit/vegetables, physically active with adequately exercise, periodicly monitoring her blood pressure and blood cholesterol. However, for non-smoker, different between those performing low or high cues to action was statistically non-significant ( $p$ $>0.05$ ).

As indicated in Table 8, a statistically significant difference in perceived susceptibility was revealed between respondents who had personal risk factors compared to those who had not. Respondents who identified themselves as overweight or obese also perceived themselves as being more susceptible to cardiovascular disease $(P=0.012)$, as did individuals who identified family history as a risk factor $(P=<0.001)$. Conversely, respondents who were physically inactive or practicing smoking felt themselves less susceptible to cardiovascular disease than respondents who engaged in regular physical activity for 30 minutes or more on most days of the week, however, it was not found statistically significant differences.

\section{Discussion}

This study provides valuable information relating to the current level of knowledge of Saudi female teachers on CVDs. Findings showed that most women possessed only limited knowledge in relation to selected facts about heart disease and prevention strategies with only $44.8 \%$ of respondents having an adequate knowledge and able to identify risk factors for CVD. This proportion is lower than the mean overall expected knowledge $(49 \%)$ which was identified in this study as the cutoff point acceptable for 'good knowledge'. However our finding is consistent with previous findings of some studies carried out in the United States of America which showed a low level of awareness and understanding of specific risk factors, particularly in terms of racial differences $[10,11,27]$.

In our present study, an age $<50$ years vs. an age $\geq$ 50 years were significant predictors $(P=0.009)$ of lower awareness of heart disease and of perceiving oneself to be less informed about heart disease among female teachers. This could be due to the misperception of younger women being more susceptible to cardiovascular disease in their future life, or perceive other health issues as being more important than cardiovascular disease, and thus showed a lower scale of perceived susceptibility to CVDs. This contrasts to the case of older women, who tend to be more aware of general health issues, or are already engaged in screening behavior related to CVDs. Our findings are consistent with a study conducted in China which highlighted that awareness was associated with an increase in age [36]. In contrast to our findings, Bisawa, et al. found that older women ( $>50$ years) were less worried about heart disease than younger women [32]. It is intereesting that very few studies have investigated age as a main factor for CVD awareness, along with associated risk factors, while the majority of studies classified patients into age categories such as adults or children (include adolescents) when studing awareness for CVDs $[37,38]$. 
In the present study, regression analysis showed no significance differences between age categories as a factor when testing perceived limited health promotion factors, despite a strong association with limited knowledge in the younger age group. It was surprising to find that only few female Saudi teachers perceived themselves to be susceptible to cardiovascular disease in this study (13.3\%). This probably indicated that participants may have known about CVD, but were unaware of their own susceptibility to CVD risk factors. Evidently, much improvement is required in terms of general knowledge of CVD risk factors, particularly in the recognition of diet and physical inactivity as a risk factor. To the best of our knowledge, this is the first study to describe the risk factors of CVD, along with relevent perceptions, among Saudi females. To date very little attention, to the best of our knowledge, has been given to the issue of women's knowledge and perceived attitudes toward CVDs in Saudi Arabia. Therefore, this study trying to help in answering the status of women at this level of education. The role of teachers usually is to contribute positively in the education of their community as well as among their students which was one of the reason that the author attempted to assess within the Saudi community.

The level of education is usually considered as an important asset in any community with which to make differences in preventive actions to control CVDs. However, in this study, education was not significantly associated with knowledge of cardiovascular disease $(P=$ 0.219). Moreover, such findings emphasize the need to investigate why women do not feel personally susceptible and why women underestimate their personal risk of cardiovascular disease. This may be attributable to a lower heart attack risk in younger women in particular. Several previous studies have found that the majority of women do not feel personally susceptible to cardiovascular disease [10].

Indepth analysis of the data acquired during our study, has enabled us to expand our understanding of the specific preventive behaviors, risk factors, and strategies for reducing CVD risk. Most of the participants in our study were aware that women who are overwieght or obese face increased risk of heart disease and diabetes. However, it is unclear whether these women placed themselves at risk when such conditions are identified or not. Similarly, the majority of female teachers surveyed understood that promoting their health through a change of eating behaviour for example, was an adequate method with which to lose weight and maintain cholesterol levels within an acceptable range. Nonetheless, practicing such behaviour was given very low priority and show more challengs in practicing such behaviours in their lives. Moreover, it appears that physicians, or other health care professionals, do not routinely discuss screening for cardiovascular disease with women, but do talk about screening for breast cancer.
It is likely that messages related to screening for CVDs are not clear, and messages relating to a woman's vulnerability are not very effective; as a consequence, very few women believe they are at risk [27]. Educational campaigns should be tailored to personalize the disease and make it more pertinent to women of all ages and educational levels. These variations in perceived risk indicate that individualized intervention approaches may be necessary to engage the target group in behaviors for lifelong CVD prevention [39].

Results from the present study showed that only $24 \%$ of female teachers had expressed high perceived severity. Similarly, a clear majority of women (98\%) perceived greater benefits from engaging in health-promoting behavior and two thirds of women expressed a wish to be more engaged in health-promoting behavior (66\%). In contrast, most participants (93.8\%) were aware that engaging in regular physical activity could help lower the risk of CVD, but few (24\%) engaged in such behavior and a very small proportion (9.5\%) engaged in all five of the benchmarked activities allocated for health-promoting behavior. Surprisingly, a majority of participants shared the view that regular physical activity and eating a low fat diet prevents or reduces the risk for CVD yet less than half of these participants engaged in preventive behavior for these major risk factors for cardiovascular disease.

Findings also revealed that women's perception of benefits in engaging in health-promoting behavior increased as their general knowledge about CVD increased. Furthermore, women who perceived fewer barriers tended to perceive greater benefits when engaging in health-promoting behavios. These findings highlight the need to tailor health interventions geared towards younger and less educated women inorder to prompt women to participate in health-promoting behavior.

What is interesting is that almost half of the respondents $(48.8 \%)$ disagreed that they do not have access to a place to be physically active yet less than a third of them engaged in this behavior. Perhaps female Saudi teachers who agreed that their family's health comes before their own had less time to engage in health-promoting behavior and perceived more barriers. A study of individuals with lower socio-economic status (SES) showed that the inherent distress of having relatively little control on coronary risk may be amplified by over-demanding social and economic environments [40]. Another study showed that the majority of people with low SES embraced the importance of lifestyle modification only after receiving their diagnosis [41]. However, Saudi Arabia is classified as a middle to high income country according to the World Bank Clasification, although similar comparisons could be common with the characteristics of CVD perception among populations with low SES. 
The present study also assessed the adoption of health promoting behaviour towards the prevention of CVD. Findings indicated that female teachers with an adequate knowledge of CVD were 1.5 times more likely to adopt promotional activities than those with inadequate knowledge $(\mathrm{AOR}=1.576 ; 95 \% \mathrm{Cl}=0.999-2.486$; $P$-value $=0.050)$. Similarly, those with high perceived benefits, those with low perceived barriers and those with high cues to action were 25.9, 1.9, and 3.6 times more likely, respectively, to adopt health promoting behaviour of CVDs than those with low perceived benefits, those with high perceived barriers and those with low cues to action $(\mathrm{AOR}=25.929 ; 95 \% \mathrm{Cl}=2.867-234.517$; $P$-value $=0.004 / \mathrm{AOR}=1.910 ; 95 \% \mathrm{Cl}=1.208-3.021 ;$ $P$-value $=0.006 / \mathrm{AOR}=3.583 ; 95 \% \mathrm{Cl}=2.096-6.126 ;$ $P$-value $<0.001$, respectively). More research is now needed to understand why a majority of Saudi female teachers are not engaged in health-promoting behavior despite facing fewer barriers. Cardiovascular disease awareness programs should be tailored towards women who are caretakers and place their family's health before their own which may also help to improve health behaviors among other family members.

Interestingly, most respondents reported some risk factors for CVD disease; the mean number of personal risk factors per respondent was three. The most frequently reported personal risk factor was lack of regular physical activity (76\%). This statistic is alarming as physical inactivity remains a major public health concern, and women are one of the least active segments of the population $[15,17]$. Furthermore, $53.8 \%$ of respondents indicated that they were either overweight or obese, although this study relied upon self-reporting, which may have influenced the response. According to the study results, perceived susceptibility to cardiovascular disease showed a statistically significant relationship with knowledge $(P<0.001)$, cues to action $(P<0.001)$ and personal risk factor $(P<0.001)$. Closer investigation revealed a statistically significant relationship between perceived susceptibility and different personal risk factors except physical inactivity and smoking. Among those participants who were overweight or obese, $82.8 \%$ did not feel susceptible to CVDs. Furthermore, of those who were physically inactive, only $13.5 \%$ felt susceptible to CVDs. There is increasing evidence that personal susceptibility for a disease may be associated with an increase in preventive health behaviors $[10,28,42]$, although this association was not observed in the present study. Our study highlights a need to address perceived susceptibility to CVD disease and the importance of addressing, understanding, and controlling modifiable risk factors in women. One of the most compelling findings from this study were the results arising from univariate and multivariate regression analysis. Surprisingly, perceived susceptibility was not a predictor for health promoting behavior. Assessment of the variables most likely to predict participation in health pro- moting behaviors revealed four statistically significant predictors: Knowledge; perceived barriers; perceived severity andcues to action. The latter was found to be the strongest predictor of health-promoting behavior among female Saudi teachers. Several factors may have influenced these results. First of all, women in this study did not feel personally susceptible to cardiovascular disease. Perhaps if women felt more vulnerable, perceived susceptibility would be a significant predictor. A relationship between perceived risk and behavior is assumed in the Health Belief Model. Increased perceived susceptibility should, therefore, be related to health promoting behavior [34]. Studies have also confirmed that misperceptions about the risk of heart disease are apparent in younger respondents, and that personal risk perception increases with age $[39,41,42]$. The mean age of respondents in the present study was 40.4 years. Perhaps results would have differed had the study been limited to women aged 55 years and older, or solicited only retired female employees.

There is a need to assess motivation for participation in health-promoting behavior that was not uncovered in the present study. "However, findings of this study will provided important data concerning perceived knowledge and behaviour regarding the CVDs among a population of women in Saudi Arabia. Therefore, from a public health perspective, it is imperative that health educational programs are needed as support to improve the level of knowledge and appropriate behaviour about CVDs in this group of population as leaders of the community educators."

\section{Limitations}

The study design prevented examination of the temporal sequence of knowledge development and change in lifestyle behaviors. Dietary habits were self-reported behavior and therefore prone to subjective recall bias. The cross-sectional nature of the study did not allow us to establish a cause and effect relationship. Furthermore, this study only included female teachers who were highly educated and in certain age categories which limited the generalizability of the study.

\section{Conclusions}

Our findings suggest that general knowledge relating to CVD risk factors and the participant's perception of risk and adopted preventive behaviors were generally low. Elder women with high levels of knowledge had a positive effect on risk perception and adopted preventive behaviors which was also linked to positive commitment to preventive behaviors for CVDs.

Correcting this misconception may have a positive impact on the desire of women to engage in health promoting behavior. It is important to conduct health education programs and health classes for female teachers with the intention of increasing their knowledge relating to CHD risk factors, their perceived risk and adopt- 
ed preventive behaviors. Future studies should include more women of diverse background, of younger age groups and with lower educational levels to understand the health beliefs related to CVD among Saudi women.

\section{Declarations}

\section{Authors' contribution}

IT and $A B$ participated in the study design, coordination, performed the statistical analysis, drafted the manuscript. IT collected the data. $A B$ interpreted the results. All authors read and approved the final manuscript.

\section{Availability of data and materials}

Available on request and reasoning explanation.

\section{Funding}

None.

\section{Declarations of Interest}

None.

\section{Ethical Approval}

This study was reviewed and approved by the internal Institutional Review Board (IRB) in the College of Public Health and Health Informatics (CPHHI), King Saud bin Abdulaziz University for Health Sciences (KSAU-HS) and King Abdullah International Medical Research Center (KAIMRC) under \# SP 17/005/R.

\section{Competing Interests}

None declared.

\section{Contribution}

It is to confirm here that all the authors were contributed equally either in the field work, analysis of the work and editing of the text.

\section{References}

1. Wells S, Rafter N, Kenealy T, Herd G, Eggleton K, et al. (2017) The impact of a point-of-care testing device on CVD risk assessment completion in New Zealand primary-care practice: A cluster randomised controlled trial and qualitative investigation. PLoS One 12: e0174504.

2. World Health Organization (2011) Global status report on noncommunicable diseases 2010.

3. Al-Daghri NM, Al-Attas OS, Alokail MS, Alkharfy KM, Yousef M, et al. (2011) Diabetes mellitus type 2 and other chronic non-communicable diseases in the central region, Saudi Arabia (Riyadh cohort 2): A decade of an epidemic. BMC Med 9: 76.

4. Mann DL, Zipes DP, Libby P, Bonow RO (2014) Braunwald's heart disease: A textbook of cardiovascular medicine. Elsevier Health Sciences.

5. Mokdad AH, Forouzanfar MH, Daoud F, El Bcheraoui C, Moradi-Lakeh M, et al. (2016) Health in times of uncertainty in the eastern Mediterranean region, 1990-2013: a systematic analysis for the Global Burden of Disease Study 2013. The Lancet Global Health 4: e704-e713.
6. WHO (2014) Noncommunicable diseases country profiles. Saudi Arabia.

7. Memish ZA, Sara Jaber, Ali H Mokdad, Mohammad A AlMazroa, Christopher J L Murray, et al. (2014) Burden of disease, injuries, and risk factors in the Kingdom of Saudi Arabia, 1990-2010. Preventing Chronic Disease 11.

8. Aljefree N, Ahmed F (2015) Prevalence of cardiovascular disease and associated risk factors among adult population in the Gulf region: A systematic review. Advances in Public Health 2015.

9. Al-Nozha MM, Arafah MR, Al-Mazrou YY, Al-Maatouq MA, Khan NB, et al. (2004) Coronary artery disease in Saudi Arabia. Saudi Med J 25: 1165-1171.

10. Mosca L, Mochari H, Christian A, Berra K, Taubert K, et al. (2006) National study of women's awareness, preventive action, and barriers to cardiovascular health. Circulation 113: $525-534$

11. Mosca L, Ferris A, Fabunmi R, Robertson RM (2004) Tracking women's awareness of heart disease an American Heart Association National Study. Circulation 109: 573579.

12. Robertson RM (2001) Women and Cardiovascular Disease: The Risks of Misperception and the Need for Action. Circulation 103: 2318-2320.

13. Alharbi NS, Almutari R, Jones $\mathrm{S}$, Al-Daghri N, Khunti K, et al. (2014) Trends in the prevalence of type 2 diabetes mellitus and obesity in the Arabian Gulf States: systematic review and meta-analysis. Diabetes Res Clin Pract 106: e30-e33.

14. Mohieldein AH, Hasan M, Al-Harbi KK, Alodailah SS, Azahrani RM, et al. (2015) Dyslipidemia and reduced total antioxidant status in young adult Saudis with prediabetes. Diabetes-Metab Res 9: 287-291.

15. Hersi A, Al-Habib K, Al-Faleh H, Al-Nemer K, AISaif S, et al. (2013) Gender inequality in the clinical outcomes of equally treated acute coronary syndrome patients in Saudi Arabia. Ann Saudi Med 33: 339.

16. Moradi-Lakeh M, El Bcheraoui C, Tuffaha M, Daoud F, Al Saeedi M, et al. (2015) Tobacco consumption in the Kingdom of Saudi Arabia, 2013: findings from a national survey. BMC Public Health 15: 611.

17. AlQuaiz AM, Siddiqui AR, Qureshi RH, Fouda MA, AlMuneef MA, et al. (2014) Women Health in Saudi Arabia: A review of non-communicable diseases and their risk factors. Pak J Med Sci 30: 422.

18. Alquaiz AM, Kazi A, Qureshi R, Siddiqui AR, Jamal A, et al. (2015) Correlates of cardiovascular disease risk scores in women in Riyadh, Kingdom of Saudi Arabia. Women Health 55: 103-117.

19. Kalaf H, AlMesned A, Soomro T, Lasheen W, Ewid M, et al. (2016) Cardiovascular disease risk profile among young Saudi women of Al-Qassim, Saudi Arabia: A cross-sectional study. Int J Health Sci (Qassim) 10: 29.

20. ALFaris NA, Al-Tamimi JZ, Al-Jobair MO, Al-Shwaiyat NM (2015) Trends of fast food consumption among adolescent and young adult Saudi girls living in Riyadh. Food Nutr Res 59.

21. Mosca L, Banka CL, Benjamin EJ, Berra K, Bushnell C, et al. (2007) Evidence-based guidelines for cardiovascular disease prevention in women: 2007 update. Circulation 115: 1481-1501.

22. Al-Nozha MM, Al-Hazzaa HM, Arafah MR, Al-Khadra A, 
Al-Mazrou YY, et al. (2007) Prevalence of physical activity and inactivity among Saudis aged 30-70 years: a population-based cross-sectional study. Saudi Med J 28: 559-568.

23. Yusuf S, Reddy S, Ôunpuu S, Anand S (2001) Global burden of cardiovascular diseases part I: general considerations, the epidemiologic transition, risk factors, and impact of urbanization. Circulation 104: 2746-2753.

24. Lloyd-Jones DM, Leip EP, Larson MG, d'Agostino RB, Beiser A, et al. (2006) Prediction of lifetime risk for cardiovascular disease by risk factor burden at 50 years of age. Circulation 113: 791-798.

25. Smith SC, Jackson R, Pearson TA, Fuster V, Yusuf S, et al. (2004) Principles for national and regional guidelines on cardiovascular disease prevention. Circulation 109: 31123121.

26. Legato MJ, Padus E, Slaughter E (1997) Women's perceptions of their general health, with special reference to their risk of coronary artery disease: Results of a national telephone survey. Journal of Women's Health 6: 189-198.

27. Hart PL (2005) Women's perceptions of coronary heart disease: an integrative review. J Cardiovasc Nurs 20: 170176.

28. Ali NS (2002) Prediction of coronary heart disease preventive behaviors in women: a test of the health belief model. Women \& Health 35: 83-96.

29. Krummel DA, Humphries D, Tessaro I (2002) Focus groups on cardiovascular health in rural women: implications for practice. Journal of Nutrition Education and Behavior 34: 38-46.

30. Ruston A, Clayton J (2002) Coronary heart disease: Women's assessment of risk--a qualitative study. Health, Risk \& Society 4: 125-137.

31. Janz NK, Becker MH (1984) The health belief model: A decade later. Health Education \& Behavior 11: 1-47.

32. Biswas MS, Calhoun PS, Bosworth HB, Bastian LA (2002) Are women worrying about heart disease? Women's Health Issues 12: 204-211.

33. Raosoft (2004) Sample size calculator. Raosoft.inc.
34. Shiplett BL (2007) An examination of knowledge, health beliefs, and health-promoting behaviors related to heart disease among university women. ProQuest.

35. Patel R (2011) Knowledge levels, health beliefs, health-promoting behaviors and sources of information for cardiovascular disease among women working in an academic setting: Southern Connecticut State University.

36. He H, Yu Y-q, Li Y, Kou C-g, Li B, et al. (2014) Dyslipidemia awareness, treatment, control and influence factors among adults in the Jilin province in China: A cross-sectional study. Lipids Health Dis 13: 122.

37. Martsevich SY, Semenova YV, Kutishenko NP, Zagrebelnyy AV, Ginzburg ML (2017) Awareness of cardiovascular disease, its risk factors, and its association with attendance at outpatient clinics in acute coronary syndrome patients. Integr Med Res 6: 240-244.

38. Amruth M, Mullick S, Balakrishna A, Prabhudeva M (2015) Assessment of awareness about cardiovascular disease risk factors and association between overweight and family history of cardiovascular disease among first-year medical students of a medical college in Karnataka. Int $\mathrm{J}$ Med Sci Public Health 4: 92-96.

39. Holt E, Cass A, Park H, Criss S, Burges M, et al. (2020) Perceived versus Actual Risk of Cardiovascular Disease in College Students. American Journal of Health Education 51: 59-68.

40. Abbott KC, Glanton CW, Trespalacios FC, Oliver DK, Ortiz MI, et al. (2004) Body mass index, dialysis modality, and survival: analysis of the United States renal data system dialysis morbidity and mortality wave II study. Kidney International 65: 597-605.

41. Oli N, Vaidya A, Subedi M, Krettek A (2014) Experiences and perceptions about cause and prevention of cardiovascular disease among people with cardiometabolic conditions: findings of in-depth interviews from a peri-urban Nepalese community. Global Health Action 7: 24023.

42. Abdela OA, Ayalew MB, Yesuf JS, Getnet SA, Biyazin AA, et al. (2019) Ethiopian university students' knowledge and perception towards cardiovascular disease risk factors: A cross sectional study. American Journal of Cardiovascular Disease 9: 1-7. 